\title{
Using Kotter's Eight Stage Process to manage an organisational change program: presentation and practice
}

\author{
Pollack, J. \& Pollack, R. \\ University of Technology, Sydney
}

\begin{abstract}
Kotter's Eight Stage Process for Creating a Major Change is one of the most widely recognised models for Change Management, and yet there are few case studies in the academic literature that enquire into how this Process has been used in practice. This paper describes a Change Manager's Action Research enquiring into the use of this Process to manage a major organisational change. The change was initiated in response to the organisation's ageing workforce, introducing a knowledge management program focusing the interpersonal aspects of knowledge retention.

Although Kotter's Process emphasises a top-led model for change, the change team found it was necessary to engage at many levels of the organisation to implement the organisational change. The Process is typically depicted as a linear sequence of steps. However, this image of the change process was found to not represent the complexity of the required action. Managing the change required the change team to facilitate multiple concurrent instances of Kotter's Process throughout the organisation, to re-create change that was locally relevant to participants in the change process.
\end{abstract}

\section{Keywords}

Change management, Organisational change, Kotter's Eight Stage Process, knowledge management, aging workforce, Action Research 
Cite as: Pollack, J., Pollack, R. (2014) Using Kotter's Eight Stage Process to manage an organisational change program: presentation and practice. Systemic Practice and Action Research, DOI 10.1007/s11213-014-9317-0

\section{Introduction}

This research reports on Action Research into an organisational change program in the Australian Finance and Insurance Sector. The use of Kotter's Eight Stage Process of Creating a Major Change (Kotter 1996) is studied in detail, providing insight into the use of this process that can be of benefit to other Change Managers seeking to apply it.

The relevance of this research becomes clear on recognising the significant divide that has been identified between the academic and practitioner Change Management communities. In 1993, it was identified that a boundary existed between theoreticians and practitioners (Buchanan 1993, p.684), with both being dismissive of each others' work, and that there was little connection between their contributions (1993, p.685). More recently, Saka (2003, p. 481) identified a similar division between how Change Management is described and how it is practiced. This situation has apparently not changed, with Applebaum et al (2012, p.764) calling for a greater emphasis on producing research in a form that is usable by those who practice Change Management.

There appears to be little research that enquires into the practicalities of using Change Management techniques to effect organizational change, either with regard to their suitability or appropriateness. Although there is a significant body of literature which provides advice for practitioners, there remains little research on how to actually apply Change Management techniques, or critically questions their effectiveness (Raineri 2011, p. 267); a lack to that this research helps to address.

Kotter's (1996) Eight Stage Process of Creating a Major Change has been recognised as one of the most well known approaches to organisational transformation (Mento et al. 2002, p.45), as the mainstream wisdom for leading change (Nitta et al. 2009, p.467), and the most compelling formula for success in change management (Phelan 2005, p.47). Kotter's work became highly sought after by leaders of organizations who were planning on implementing organizational change initiatives (Brisson-Banks 2010, p.248). The Process "... became an instantaneous success at the time it was advocated and it remains a key reference in the field of change management" (Applebaum et al. 2012, p.765).

Given the popularity of Kotter's Eight Stage Process it may be reasonable to assume that claims of a divide between research and practice are not relevant in this case. However, a thorough study of the literature by Applebaum et al. (2012) has revealed that this is not necessarily true. Their review of the Change Management literature revealed that "...most of the evidence found during the search points to data that has been compiled by Kotter himself ... In essence Kotter validated Kotter" (Applebaum et al. 2012, p.776). Academics appear to have used Kotter's findings about Change Management as if verified and tested. "Kotter's change management model appears to derive its popularity more from its direct and usable format than from any scientific consensus on the results" (Applebaum et al. 2012, p.764).

A variety of reviews of the field of organisational change can be found in the literature (e.g. Cao and McHugh, 2005). Although some authors (e.g. Tsoukas and Papoulias 2005) refer to an abundance of case studies examining organizational change, there are few case studies of changes managed using Kotter's Process (Applebaum et al. 2012, p.776). The weight of research that references Kotter's work does not investigate how the Process can be used, but instead either discusses Kotter's writing in the context of the broader literature on Change Management, or uses the Process as a framework for conducting a post-hoc analysis of a change (e.g. Yauch 
Cite as: Pollack, J., Pollack, R. (2014) Using Kotter's Eight Stage Process to manage an organisational change program: presentation and practice. Systemic Practice and Action Research, DOI 10.1007/s11213-014-9317-0

and Steudel 2002; Sidorko, 2008; Smith 2011; Casey et al. 2012; Nitta et al. 2009; Goede 2011; Gupta 2011).

Studies by Cole et al (2006, p.363) and Paper et al. (2001, p.85) have found the actual execution of a change to be one of the key factors in determining success or failure. Of the various ways in which Kotter's work has been used in the Change Management literature, it is arguably Action Research, rather than literature reviews or post-hoc analyses, that have the greater potential to contribute to improved execution. Some case studies of changes managed using Kotter's Process do stand out (e.g. Springer et al. 2012; Lintukangas et al. 2009; Day and Atkinson 2004; Ansari and Bell 2009; Joffe and Glynn 2002), and it is to this small but important literature to which this research contributes. This research critically examines how Kotter's (1996) Eight Stage Process of Creating a Major Change has been used to manage an organisational change; a process that despite its popularity, has rarely been studied in the academic literature.

\section{The Eight Stage Process of Creating a Major Change}

The Eight Stage Process is "...as a vision for the change process" (Mento et al. 2002, p.45) describing a series of steps to be taken to achieve mandated organisational changes. A wide variety of models for managing organisational change exist in the literature (Sidorko 2008, p.307; Stewart and Kringas 2003, p.676; Buchanan 1993, p.684; Smith 2011, p.115; Pillay et al. 2012, p.59), and is not the place of this research to analyse Kotter's Process in relation to other models. Readers are instead referred to authors who have already done this (e.g. Brisson-Banks 2010; Stewart and Kringas 2003). However, it is worthwhile to note some ways in which the Process has been characterized: as placing a strong emphasis on leadership (Pillay et al. 2012, p.61; Raineri 2011; Choi et al. 2011, p.12) and viewing change as top-led (Abraham et al. 2002, p.36; Choi et al. 2011, p.12; Day and Atkinson 2004, p.258). Kotter's approach has also been described as focusing on organisational culture (Casey et al. 2012, p.112), and of being typical of private sector change models (Stewart and Kringas, 2003). Disagreement also exists, with some (Pillay et al. 2012, p.60) describing the Process as centrally planned change, while By (2005) has described it as emphasising an emergent, rather than a planned, approach to Change Management.

Kotter's Eight Stage Process of Creating a Major Change as detailed in Leading Change (1996) and later works can be summarised as follows:

1. Establishing a sense of urgency

2. Creating the guiding coalition

3. Develop a vision and strategy

4. Communicating the change vision

5. Empowering broad-based change

6. Generating short-term wins

7. Consolidating gains and producing more change

8. Anchoring new approaches in the culture

The efficacy of Kotter's Process has been broadly supported in the literature (e.g. Ansari and Bell 2009, p.160; Cegielski et al. 2006, p.311). Despite its popularity, the Process has also been criticised. It has been claimed that this, and other, Change Management processes describe what has to be done but provide little detail in how it should be achieved (Pfeifer et al. 2005, p.297), and that it is not sufficiently detailed to guide Change Management in all situations (Applebaum et al. 2012, p.775).

Conversely, the Process has also been criticised as not general enough for some kinds of change (Ansari and Bell 2009, p.157), and of being overly planned, and 
Cite as: Pollack, J., Pollack, R. (2014) Using Kotter's Eight Stage Process to manage an organisational change program: presentation and practice. Systemic Practice and Action Research, DOI 10.1007/s11213-014-9317-0

therefore not representation of the realities of organisational life (Hay et al. 2001, p.243). However, these criticisms need to be tempered by Sidorko's (2008, p.316) observation that "...no single model can provide a one-size-fits-all solution to organisational change."

Springer (2012) provides a detailed case study which reviews the use of the Process to implement a cultural change at the Boise State University School of Nursing. The case provides detail about the changes that were implemented within the organisation, but does not focus on how the process was used to facilitate this change. This case study leaves the reader with the impression use of Kotter's Process was uncontentious. Perhaps this was the case, although without specific comment to this effect it is not possible to say.

The Process was also used to facilitate change in an aerospace industry study presented by Day and Atkinson (2004). In this case, the Process was used as a planning tool and to communicate the nature of the change to procurement functions in the early stages of the change program. However, the practitioners in this case study had limited success using the Process as a guide for future action, finding the Process to be of "...limited use over and above the raising of personal awareness about the range of factors that are to be considered throughout a change programme..." (Day and Atkinson 2004, p.266).

Kotter's Process was also used in the implementation of a Shell Gabon strategic cost initiative in the initial planning phases of the change program (Ansari and Bell, 2009). However, the change team found that not all stages of Kotter's Process suited their environment, needing to add other conceptual frameworks. Joffe and Glynn (2002) also present a study of the use of Kotter's Process in the pharmaceutical industry, while Lintukangas et al. (2009) present a case study of a forestry company which aimed to follow Kotter's Process in implementing an organisational change. However, neither of these latter two cases provide significant critical reflection on the use of the Process, and so are of limited use in understanding how the Process can be applied in practice.

\section{Methodology and structure of the paper}

This research was conducted at UGF (a pseudonym), an Australian organisation in the Finance and Insurance Sector with over 10,000 employees and offices worldwide. The Change Manager used Kotter's Eight-Stage Process of Creating a Major Change to guide and structure Change Management action, and the use of this process forms the focus for this research.

This research was managed using Action Research (AR). There are a wide variety of forms of AR, although it would be fair to say that most could be described as cyclic and reflective methodologies (Swepson 2003, p. 102), which are primarily focused on intervention, rather than observation (Midgley 2003, p. 81). AR is an approach to research which allows a researcher to engage in an organisation, and simultaneously create knowledge about that process (Olesen and Myers, 1999, p. 323).

AR is particularly appropriate for organisational settings, where the need to produce organisational outcomes may be more significant in securing ongoing research participation than the promise of research outcomes. AR requires involvement in problem situations and a "... readiness to use the experience itself as a research object about which lessons can be learned by conscious reflection" (Checkland and Scholes 1990, p. 16). AR has also been identified as appropriate for organisational change research, as it assists in developing an understanding of the ways that social 
Cite as: Pollack, J., Pollack, R. (2014) Using Kotter's Eight Stage Process to manage an organisational change program: presentation and practice. Systemic Practice and Action Research, DOI 10.1007/s11213-014-9317-0

systems change (Lau 1999, p. 149), and has been used to study a wide variety of business problems, including: organisational change and transformation; marketing; product development; manufacturing; engineering; information systems and ecommerce; accounting; small business; and management development (Sankaran and Tay 2003, pp. 1 - 2).

Flood $(1999$, p. 53) has noted the development of a unique form of AR as one of the key strands in Checkland's work. Checkland's FMA model has been identified as one of the most widely used forms of AR (Champion 2007, p. 455), and it is this model which has been followed in this research. The main components of this model are a research framework (F); a methodology (M); and an area of application (A). Simply, particular "... linked ideas $F$ are used in a methodology $M$ to investigate an area of interest A" (Checkland and Holwell 1998b, p. 13). Being explicit about these three elements may lead to learning not only about the area of application, but also about the adequacy of the methodology and the research framework (Checkland and Holwell 1998b, p. 13). Indeed, the majority of learning resulting from the research presented in this paper is at the level of methodology.

Clear distinction between a framework of ideas and a methodology for the organised application of those ideas differentiates this approach to AR from others (Checkland 2003, p. 291). Most other AR "... omits the need for a declared-in-advance intellectual framework of ideas, a framework in terms of which what constitutes 'knowledge' about the situation researched will be defined and expressed" (Checkland and Holwell 1998a, pp. 22 - 3). What constitutes knowledge in a problem situation should not be taken as given. In defining $F$, the researcher is in effect defining the epistemology of the research and defining what will count as knowledge (p. 24). Declaring the intellectual framework for an AR project can be thought of as a way of contextualising the research in relation to the range of possible forms of knowledge extant, allowing any research findings to be appropriately judged and understood.

It is perhaps because of clear identification of the components of research that Checkland's FMA model has been found to add rigour (Sarah et al. 2002, p. 537) and provide clarity (p. 539). The FMA model has been used to study organisational change (Molineux and Haslett 2002), and readers are referred to West and Stansfield (2001, p. 251) for an in-depth review of the use of the FMA model.

In terms of the FMA model, this research can be summarised as follows:

- $\mathrm{F}$ : Interpretivist epistemology and the academic literature on organizational change

- M: Kotter's Eight Stage Process of Creating a Major Change

- A: Action taken at UGF

Data for this paper was gathered through semi-structured interviews between the authors as a way of facilitating reflection, one of whom was the change manager for the Knowledge Management Program at UGF. At the time of initial submission of this research for publication, the organisational change had been running for over two years.

The remainder of this paper will be structured according to Kotter's Process. Each Stage will be discussed in terms of principles for action as described in the literature, before actions taken at UGF are examined. Observations and conclusions about the overall use of the Process will then follow. 
Cite as: Pollack, J., Pollack, R. (2014) Using Kotter's Eight Stage Process to manage an organisational change program: presentation and practice. Systemic Practice and Action Research, DOI 10.1007/s11213-014-9317-0

\section{Stage 1: establishing a sense of urgency}

The first stage in Kotter's Eight Stage Process is to create a sense of urgency; an awareness of the need for the organisation to change. Kotter notes the failure to create a sense of urgency to be the single biggest error made when trying to change organisations (Kotter 2008, p.viii), and has written a whole book, A Sense of Urgency, exclusively focusing on this stage.

"Establishing a sense of urgency is crucial to gaining needed cooperation. With complacency high, transformations usually go nowhere because few people are even interested in working on the change problem. With urgency low, it's difficult to put together a group with enough power and credibility to guide the effort (Kotter 1996, p.36).

Complacency, rather than a desire for change, has been identified as more likely to be the norm in established organisations (Kotter 2008, p.15). Considerable effort may be required to motivate organisational personnel to invest their time and effort and to put up with the inconveniences of change (Ansari and Bell 2009, p.157).

Although in Australia the Financial and Insurance Services sector has a relatively younger workforce than many other sectors (Department of Education, Employment and Workplace Relations 2010, p.12), the issues that could result from a failure to respond to their aging workforce were apparent to the senior management team at UGF. It was identified that aging workforce issues could negatively impact upon core business areas if left unaddressed. In particular, senior product roles were identified as under threat, due to a lack of younger personnel able to fill these roles.

An aging workforce is typically represented as a threat; as a "... demographic time bomb..." (Crampton et al. 1996, p.243), a "...baby-boom-retirement tsunami..." (Leonard and Swap 2004, p.90), or "...a threat to sustaining competitive advantage" (DeLong 2004, p.19). However, the risks associated with an aging workforce are typically faced equally by all companies within that industry sector. Risks can be considered to include both threat and opportunity (Hillson 2003). There is an opportunity for competitive advantage for those companies who respond most effectively to these issues.

Senior management at UGF established a Knowledge Management Program to mitigate retirement knowledge loss. The initial focus in the Knowledge Management Program was on exploring the risks associated with continuing with business as usual, and why change was needed. Change Management personnel reported that the need for change was easy to sell as a message, due to widespread awareness of the looming demographic shift, but that it was important to raise awareness that this was an issue that the company was looking to do something about.

\section{Stage 2: creating the guiding coalition}

The second stage in Kotter's Process involves forming a group who have enough power to lead the change (Kotter 1996, p.21). Guiding coalitions for the Knowledge Management Program were created at multiple levels. Most prominently, the executive management coalition was championed by the CEO and direct reports, and provided ongoing strategic direction for the program.

The General Management Advisory Group, the second coalition, was also formed to provide project governance. It has been identified that it is often problematic to identify isolated factors that are responsible for the successful implementation of 
Cite as: Pollack, J., Pollack, R. (2014) Using Kotter's Eight Stage Process to manage an organisational change program: presentation and practice. Systemic Practice and Action Research, DOI 10.1007/s11213-014-9317-0

changes in organisations (Van der Meer 1999). However, Helm and Remington (2005) have identified that the role of program sponsor is vital. This is particularly true in complex organisational change programs (Remington and Pollack, 2007). The involvement of these groups of senior personnel met the need for a strong guiding coalition for the Program, something that Kotter (1996) identifies as essential.

A third prominent coalition was formed at a technical level of the organisation. One of the projects within the program involved the development of a mentoring network, using a risk based approach to knowledge management consistent with the approach reported on by Sherman (2008). The Change Manager put considerable effort into bonding the senior personnel invited to be coaches into a group. It was made clear that the success of the Program depended upon their involvement and drive for change. The group received personalised communication from the sponsor EGM and CEO, and would go on to have guiding influence beyond the limits of their project.

\section{Stage 3: develop a vision and strategy}

UGF was described by the Change Manager as an organisation that culturally understands and responds to risk. One of the key strengths of the organisation lay in the knowledge of talented senior technical personnel. The organisation was already in a strong market position. However, long-term contextual changes threatened this key strength. Upon retirement employees take the unique skills, knowledge, experience and relationships that they embody with them as they walk out the door. This is a commonly acknowledged threat (e.g. Malone 2002, p.112; DeLong 2004; Burke and $\mathrm{Ng} 2006$, p.88). Transfer of knowledge from an older generation of experienced personnel to the generations following was considered vital to UGF maintaining performance. This is consistent with the literature. Burke and $\mathrm{Ng}$ (2006) noted that those organisations that effectively transfer knowledge between generations will be the least susceptible to issues associated with retiring workers (p.88). Knowledge transfer programs are acknowledged as a significant response to an aging workforce in a wide variety of research (IAEA 2004, pp.18-9; Krail 2005, p.35; Sherman 2008, p.45). The vision for the Program was to minimise this large risk to the organisation's competitive advantage, and was mostly defined in negative terms, as the need to avoid the consequences of inaction.

The strategy to address this issue involved launching a wide variety of projects, including: a mentoring project; developing communities of practice; role redefinition to allow for accelerated specialist development; the introduction of a graduate program; introduction of software supported discussion forums and analysis tools; development of seminars focused on knowledge sharing; and a retirement preparation project focusing on retention and workload issues. It was found that developing a vision and gaining acceptance for projects was relatively uncontentious. This can be attributed to broad and common acceptance of the need to change. Of the four types of organisational change identified by Cao et al. (2004, p. 105), this program would come to emphasise change of cultures and values.

\section{Stage 4: communicating the change vision}

The fourth Stage in Kotter's Process is to communicate the vision for change. However, Kotter notes that managers underestimate the amount of communication required to develop a consistent understanding, an effort which may be hampered by inconsistent messages, and lead to a stalled change implementation (1996, p.85). Other research has observed that "...in any company there is twice as much discussion about the weather than about new strategies" (Pfeifer et al. 2005, p.302). 
Cite as: Pollack, J., Pollack, R. (2014) Using Kotter's Eight Stage Process to manage an organisational change program: presentation and practice. Systemic Practice and Action Research, DOI 10.1007/s11213-014-9317-0

Ansari and Bell (2009, p.159) have identified the need to communicate the change as one of the two most important stages in Kotter's Process.

Kotter identifies the error of "...undercommunicating the vision by a factor of 10 (or 100 or even 1,000)..." (1996, p.9). In this organisational change at UGF more time and effort was devoted to spreading the message and developing the visibility of the Program than any other Program activity. However, adequately communicating the program vision proved to involve more than repetition; something which is consistent with Sidorko's (2008, p.310) findings about change communication.

The change team focused on two broad groups of activities in communicating the vision: visible senior support; and harnessing existing activities. Senior leaders were regularly enlisted to talk about the need for change, and this was found to be an effective strategy in developing senior support. For instance, on one occasion it was noted that an executive appeared bored with the progress reports he had received. However, when he was given slides and asked to present on the topic he became interested. In front of an audience, he was animated and engaged, and afterwards requested more material to present. This approach of engaging senior leaders through presentation to their teams and to other product areas was reported as effective. It was also reported that the change team needed to take the initiative to find new forums at which senior leaders could present, rather than assuming this would happen without prompting. Despite CEO endorsement of the Program, initiative could not be assumed.

The change team built on already planed activities within the organisation, often taking senior managers' presentation slides on other topics to draw out links to the Program, rewriting parts of the presentations to provide examples of the importance of the change, including for the CEO. One example included the annual CEO and Executive road-show, which was adapted to feature a strong emphasis on the Program. The change team also approached the EGM of HR and suggested that he may also want to discuss the Program at the road-show. This gave the EGM of HR an opportunity to join a politically expedient movement, and helped to promote the Program in multiple forums; at the road-show itself, and later again when the EGM of HR reported to his leadership team.

Developing relationships with the organisation's communications department also proved significant. Good news articles about the Program, such as updates about recent coaching workshops, would be posted on the intranet. The change team nurtured positive relationships with the communications department, which helped to keep news about the Program at the top of the intranet news list for longer and with greater prominence.

\section{Stage 5: empowering broad-based change}

The fifth stage in Kotter's Process involves removing obstacles to change, changing structures or systems that undermine the vision, and encouraging innovative ideas (Kotter 1996, p.21). As relationships with the communications team helped in the previous stage, relationships with HR and other business units helped to remove structural barriers to empowerment. For instance, unit business plans were centrally controlled for some units, and locally controlled for others. The change team talked to each unit individually and to the group overseeing central control of business plans to have aspects of the Program included in all business plans. Relationships with key personnel in HR helped to ensure approval, and when it was approved the relationships with the communications team helped to ensure that the Program priorities featured prominently in unit plan documentation. 
Cite as: Pollack, J., Pollack, R. (2014) Using Kotter's Eight Stage Process to manage an organisational change program: presentation and practice. Systemic Practice and Action Research, DOI 10.1007/s11213-014-9317-0

Many of the blocks removed were at the project, rather than the program, level and can be most clearly illustrated through reference to the mentoring project. To ensure coach performance, all coaches attended training. The need for coaching training is consistent with observations in the literature (Lubit 2001, p.176). It has been identified that many organisations have lost the ability to coach upcoming generations (Crawford et al. 2006, p.727). Coaches were also provided with a resource to assist with ongoing coaching on coaching.

The sponsor encouraged coaches, protégés, and participants to experiment, with the intention of empowering them to take independent action. Coaches were allowed to define their coaching roles to suit their interests and skills. For instance, at one Community of Practice it was revealed that a coach had taken his protégés on a field trip. Another coach felt that their protégés' negotiation skills needed to be further developed, and engaged an external training provider. These actions were neither suggested nor pre-sanctioned, but when revealed were actively supported.

Emphasis was also placed on ensuring that the coaches knew they had senior management support. At one point, a coach approached the change team identifying that a protégé's manager was making participation in the Program difficult. The Change Manager didn't have the line authority to remove the block, but had access to those who could, and did, resolve such issues.

The existing role design for many protégés also did not align with the Program goals, with many protégé's in generalist product roles that did not allow for rapid specialist development. The GM who oversaw many protégés was opposed to changing their role description, so the change team started talking to everyone they could to garner support. Coaches were surveyed and approximately $80 \%$ identified specialisation as the better option. It became clear that public opinion was for role specialisation and so the GM redefined roles for the protégés.

\section{Stage 6: generating short-term wins}

Short-term wins help to demonstrate the viability of change and to build momentum. Kotter (1996, p.123) identifies that short-term wins need to be visible; unambiguously successful; and clearly related to the direction of change. Although not all researchers consider short-term significant in all change programs (Ansari and Bell 2009 , p.159), they did play a significant part in the management of the Knowledge Management Program. The change team's role involved less of the direct creation of short-term wins than in advertising the successes of those wins.

Survey results were one way that the progress was advertised within UGF. For instance, although at the time of writing it was too early to prove the impact of the mentoring project on the speed of development of specialist product knowledge, the project has been lauded as successes. Survey responses indicated a positive perception of the impact on development speed. For instance, $94 \%$ of coaches had noticed a positive change in protégés' confidence and knowledge. Survey results were also used in the case study documented by Springer et al (2012, p.84), although in that case they were used to develop a sense of urgency rather than to communicate short-term wins.

Another tactic used to raise awareness of Program progress was through storytelling. Kotter (2008, p.54) has noted that "Neurologists say that our brains are programmed much more for stories than for PowerPoint slides and abstract ideas", and has referred to "...the incredible power of good stories to influence behaviors over 
Cite as: Pollack, J., Pollack, R. (2014) Using Kotter's Eight Stage Process to manage an organisational change program: presentation and practice. Systemic Practice and Action Research, DOI 10.1007/s11213-014-9317-0

time..." (Kotter 2005, p.142). Indeed, Kotter's Our Iceberg is Melting (2005) is almost entirely delivered through story. The significance of using metaphors and compelling stories to develop awareness of the need for change or to explain a specific initiative has also been identified by Roberto and Levesque (2005, p.56).

The change team sought out examples of positive change throughout UGF that illustrated the successes of the Program, including structuring stories based on Denning's framework for the springboard story (2001), a story structure designed to facilitate and encourage organisational change. Senior leaders were then supplied with a drip-feed of new scripted stories for upcoming organisational events.

The change team found that some coaches started to comment that change was too hard to continue; that they didn't feel they had made progress. Many of the changes that had already occurred were intangible and easy to forget. Communicating shortterm wins were useful in soothing flagging spirits, but finding ways of communicating intangible and diffuse wise often required considerable effort.

\section{Stages 7 and 8: consolidating gains and producing more change, and anchoring new approaches in the culture}

At the time of interview, the Knowledge Management Program was in the seventh stage of Kotter's Process. The Program had gained considerable momentum through the short-term wins, the involvement of the Program's guiding coalitions of senior personnel, and the persistent use all possible communication channels to increase the visibility of the Program.

The change team now had to deal with the consequences of their success. Due to increased access to senior management and a perception that they were on a fasttracked development path, participants in some projects were perceived as members of an 'exclusive club'. In the early stages of the Program this had contributed to an aura of success. However, the 'exclusive club' approach would not suit the larger and more inclusive group involved in the next stage of growth. The change team were coming to terms with the need to change their personal conceptualisation of the Program.

During Stage Seven other projects that were contributing to aligned goals and relatable projects that were in the early stages of initiation were brought under the Program banner. It was reported that effort was required to keep the Program true to the vision during this stage of growth and to resist the manoeuvres of other parties from subverting, or changing, the Program approach. For instance, some parties were interested in changing the focus from developing interpersonal networks of knowledge sharing to an IT-focus on developing knowledge repositories. However, it has been identified in the literature that tacit knowledge is not easily codified and that "While it's true that merely describing experiences to people (or telling them what to do or giving them rules) may create some mental receptors upon which to hang experience, the tacit dimensions of an expert's deep smarts have to be re-created to take hold" (Leonard and Swap 2004, p.94). At UGF, knowledge was being re-created through protégés' vicarious experience of mentors' stories, and access to worldviews developed over decades in the industry. A move towards a greater emphasis on IT investment over interpersonal network development was resisted.

Stages Seven and Eight of this change process were reported as likely to take a long time to complete. It has been noted that large scale change can take a long time to complete, and that this is particularly true in larger organisations (Kotter 1996, p.132). New messages were being sought to maintain organisational interest in the 
Cite as: Pollack, J., Pollack, R. (2014) Using Kotter's Eight Stage Process to manage an organisational change program: presentation and practice. Systemic Practice and Action Research, DOI 10.1007/s11213-014-9317-0

change. "Whenever you let up before the job is done, critical momentum can be lost and regression may follow. Until changed practices attain a new equilibrium and have been driven into the culture, they can be very fragile" (Kotter 1996, p.133). As noted by Applebaum et al. (2012, p.776) Stages 7 and 8 are complicated to evaluate. It will likely be many years before definitive statements can be made about how well the Knowledge Management Program was embedded in the culture of UGF.

\section{Discussion of the use of Kotter's process}

It is difficult to make categorical statements about the efficacy of an approach to change, due to the complexity of their use in practice (Applebaum et al. 2012, p.776). "This is one of the inherent problems with organisational change management; nobody can know what would have happened if a different course of action (or no action at all) had been taken ..." (Reissner et al. 2011, p.427). With regard to evaluating the use of a process, Checkland and Scholes (1990, p.299) have noted that "...there is in principle no way in which it could be proved or disproved that this was the best way to do it, or that a more competent use ... would have achieved the results more quickly." These statement are generally true for any assessment of Change Management involving the implementation of a process by unique practitioners in an unique context. However, it is possible to make observations of the interpretation of the approach which may be of benefit to future practitioners.

Kotter's Process has been described as "...structured linear steps" (Day and Atkinson 2004, p.257), an “...'n' step change...” process (p.265), “...a linear progression..." (Nitta et al. 2009, p.483) or "...a sequential procedure..." (Pfeifer et al. 2005, p.297). Indeed, Kotter (1996) identifies the "...importance of sequence..." (p.23) and that "...skipping even a single step or getting too far ahead without a solid base almost always creates problems" (p.23). Other writers have criticised linear approaches as they "...they lack flexibility to deal with the vast assortment of problems and issues that may be experienced during change" (Sidorko 2008, p.308), and that a traditional reading of Kotter's work does not account for how democratic organisational change can be (Reissner et al. 2011, p.426).

It is clear from the number of authors that have interpreted Kotter's work in this way, that his writing gives the impression that organisational change involves one sequence of movement through the eight Stages. However, Kotter does acknowledge that earlier stages may have to be revisited, suggesting the possibility of some break to the sequence. Although this research paper has related the change at UGF in linear fashion, use of the Process in practice was found to be significantly more complex than a single linear series of steps. The distinguishing characteristic is not whether the change was linear or cyclic, or whether it was top-down or bottom-up change. The distinction being made is between viewing change as one cohesive Process or the sum or many coordinated Processes.

At UGF, there were many different stakeholder groups involved in delivering the change; from the many guiding coalitions to project teams delivering individual pieces of work. These different groups started the change process at different times, and multiple concurrent instances of the Process were needed. To engage with stakeholders it was necessary to treat them individually, not as part of a one-size-fitsall package. Kotter's description of the Process does not make explicit allowance for this. Nonetheless, the Eight Stage Process was found to be an accurate description of the change process at the individual group level. This is depicted in Figure 1. 


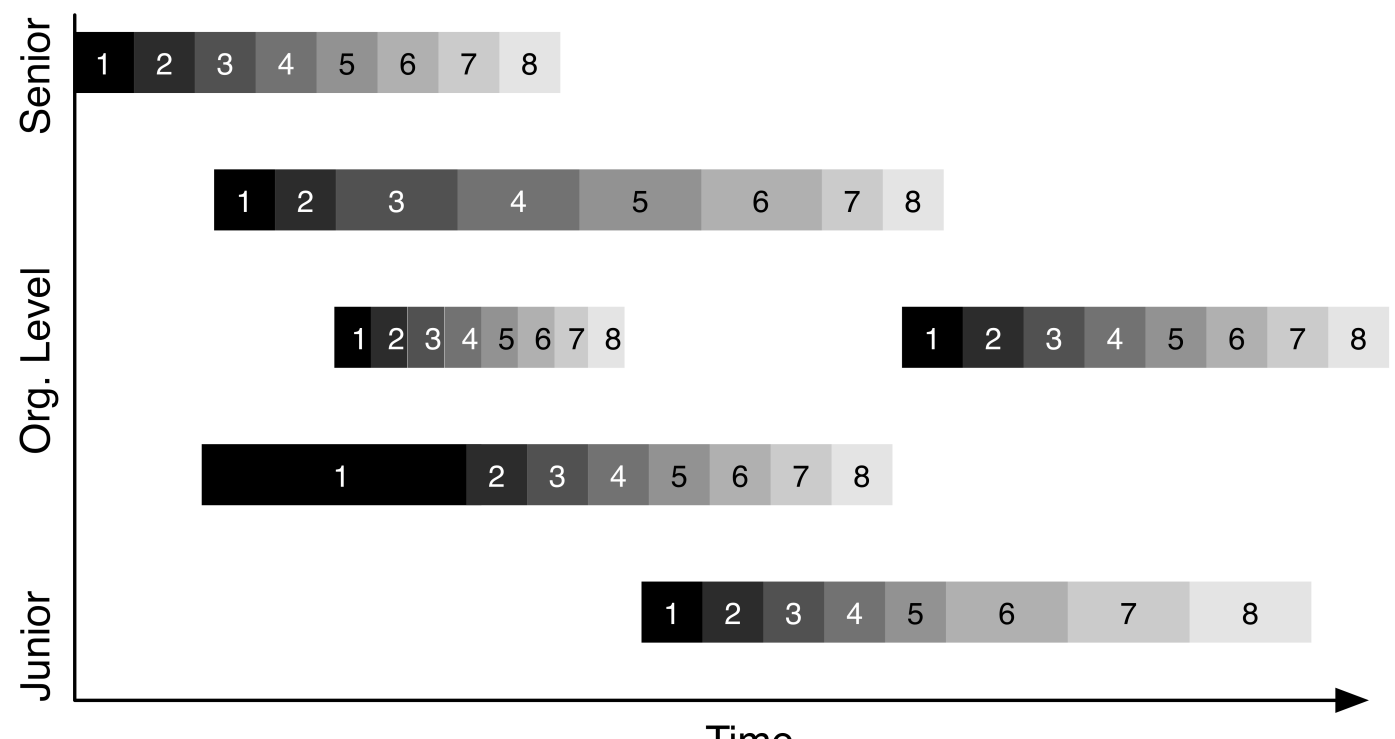

Time

Figure 1: Multiple concurrent change processes through the organisation

Different stakeholder groups also moved through the stages at different speeds. For instance, little effort was needed to develop a sense of urgency in the coalition of EGMs. By contrast, ten months after the Program had started, the change team met with a group of managers five levels below the CEO who had not yet had much involvement in the Program. It was clear that the managers were not engaged. Although the organisation was celebrating the short term wins from other parts of the Program, this group did not understand the urgency. In order to engage this group, it was necessary to start the change process again separately. This involved bringing in senior managers to discuss the need for change, forming this group into their own coalition to lead their manifestation of the change, and defining a vision for what the change meant for them. Senior management's vision for the change needed to be recreated at a local level for this group to own their part of the change process.

This can also be seen in discussion of Stage 2. One interpretation of this stage suggests the need to create a single guiding coalition. Kotter's work tends to only refer to a guiding coalition in the singular, and is silent on the possibility of using multiple distributed guiding coalitions. However, Day and Atkinson criticise the idea of a guiding coalition as unable to address a "...multiplicity of agendas..." (2004, p.265), and it is possible that a single coalition would not have been able to address all agendas in the Program at UGF. However, in this Program multiple guiding coalitions were created at different organisational levels and in different areas of the organisation. One executive coalition set the original strategy, and a second significant coalition addressed governance issues, while a third took ownership of two prominent projects. In addition, as the Program developed, still more groups provided leadership for the parts of the Program that were relevant to them, with the change management team providing a guiding force to maintain alignment between these different groups. Each coalition was given responsibility for pushing change at a level that was appropriate to their scope of work. This finding echoes an observation made by Sidorko (2008, p.310).

"...what eventuated was that several "guiding coalitions" were established, not necessarily at the same time and with different yet complementary charges that were appropriate to the need at the particular point of time in the 
Cite as: Pollack, J., Pollack, R. (2014) Using Kotter's Eight Stage Process to manage an organisational change program: presentation and practice. Systemic Practice and Action Research, DOI 10.1007/s11213-014-9317-0

change process. Kotter makes no allowance for such complexities." (Sidorko 2008, p.310)

Kotter's work remains ambiguous and relatively silent with respect to the issue of whether change should be managed as a single instance of his Process or as multiple instances distributed throughout an organisation. His silence on this issue may be deliberate, with the intention of preserving a simple account of the process of organisational change. While this simplicity may have aided in communicating the change process, it may also have given the impression that change in a large organisation can, or should, be managed as a single iteration through the Process, with all parts of the organisation moving in unison. Such an approach that would have been problematic at UGF where different stakeholder groups started the Process at different times, and progressed through it at different speeds.

At an organisational level, when roughly summing the effort applied by all stakeholder groups at UGF, each of which were at different stages of progress through the Process, the organisation could be depicted as moving through the Eight Stage Process in a linear way (See Figure 2). This suggests that it is important to think of the change process at both the organisational level and at the level of separate stakeholder groups. Kotter's Eight Stage Process is linear, but for largescale change that top-level appearance of linear sequence may be made up of many small stakeholder groups moving in parallel, with the sequence representing an overlapping change in focus over time. This also suggests that an effective change team will need the flexibility to be able to work on many stages of change at once, depending on the stakeholder group they are engaging with at that time.

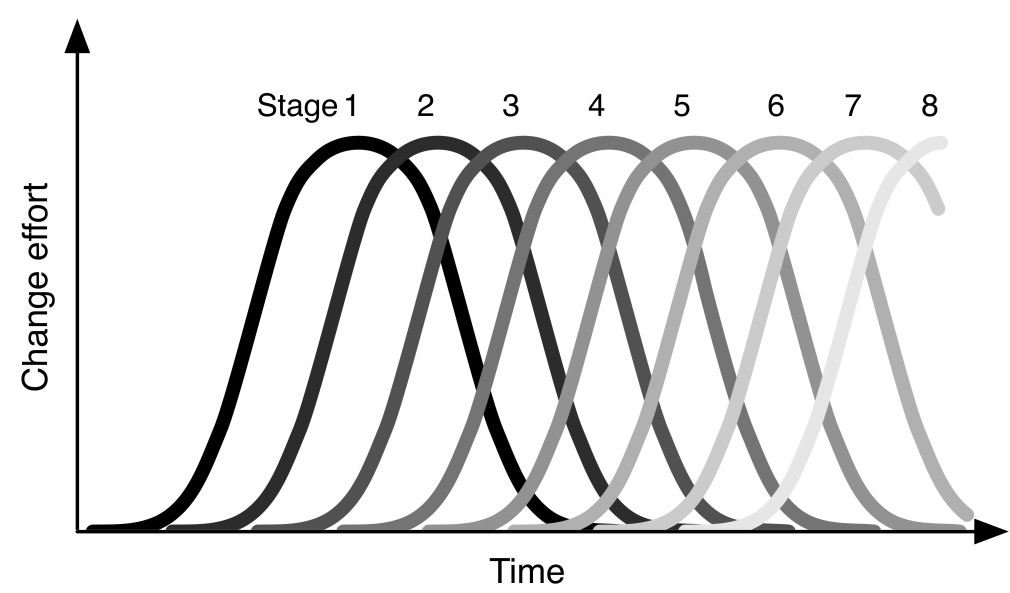

Figure 2: Overlapping focus on different Stages during the change

\section{Conclusion}

This paper has discussed the case of an organisational change using Kotter's Eight Stage Process for Creating a Major Change at UGF, a company in the Australian Finance and Insurance Sector. Kotter's Process was found to be an effective way of managing the change, although some adaptation was required to suit the Process to the needs of the organisation. Kotter's work has been interpreted by other authors as suggesting that the Process should be used as a simple set of linear steps. However, it was found that in practice the use of the Process was significantly more complex.

Although the change started with the UGF leadership team, developing momentum within the leadership team was not sufficient to create the change. Many other 
Cite as: Pollack, J., Pollack, R. (2014) Using Kotter's Eight Stage Process to manage an organisational change program: presentation and practice. Systemic Practice and Action Research, DOI 10.1007/s11213-014-9317-0

stakeholder groups needed to be separately engaged by the change team, first through developing a sense of urgency within these teams, then forming a group to lead the change, and defining what the change would locally mean to them. The Process of creating change was found to be linear, but throughout the organisation it was comprised of multiple instances of the Process, each with overlapping stages, and each moving at their own speed, with the change management team providing support to maintain strategic alignment between these processes.

This research has contributed to a much needed link between Change Management theory and practice. It has also contributed to the small literature which enquires how Kotter's Process can be applied in practice, providing some validation of one of the more popular change models; one which has hereto been the subject of little external practice based research. This research has provided one example, but more are needed to enquire into how others have applied Kotter's Process in practice so that practitioners have greater opportunity to learn from others' experience in changing their organisations.

\section{Reference list}

Abraham M, Sullivan T, Griffin D (2002) Implementing NAGPRA: the effective management of legislated cange in museums. Management Decision 40:35-49.

Ansari S, Bell J (2009) Five easy pieces: a case study of cost management as organizational change. Journal of Accounting \& Organizational Change 5:139-167.

Appelbaum S, Habashy S, Malo J, Shafiq H (2012). Back to the future: revisiting Kotter's 1996 change model. Journal of Management Devleopment 31:764-782.

Brisson-Banks C (2010) Managing change and transitions: a comparison of different models and their commonalities. Library Management 31:241-252.

Buchanan D (1993) Review of 'A Strategy of Change: Concepts and Controversies in the Management of Change'. Journal of Management Studies 30:684-686.

Burke R, Ng E (2006) The changing nature of work and organizations: Implications for human resource management. Human Resource Management Review 16:86-94.

By R (2005) Organisational Change Management: A Critical Review. Journal of Change Management 5:369-380.

Cao G, Clarke S, Lehaney B (2004) The Need for a Systemic Approach to Change Management - A Case Study. Systemic Practice and Action Research 17:103-126.

Cao G, McHugh M (2005) A Systemic View of Change Management and Its Conceptual Underpinnings. Systemic Practice and Action Research 18:475-490.

Casey M, Payne W, Eime R (2012) Organisational readiness and capacity building strategies of sporting organisations to promote health. Sport Management Review 15:109-124.

Cegielski C, Hall D, Rebman C (2006) Enterprise resource planning systems implementation success. International Journal of Information Systems and Change Management 1:301-317.

Champion D (2007) Managing Action Research: the PEArL Framework. Systemic Practice and Action Research 20:455-465.

Checkland P (2003) From Optimizing to Learning: A Development of Systems Thinking for the 1990s. In: Midgley G (ed) Systems Thinking, Volume III. Sage, London, pp 290303.

Checkland P and Howell S (1998a) Information, systems and information systems - making sense of the field. Wiley, West Sussex.

Checkland P and Holwell S (1998b) Action Research: Its Nature and Validity. Systemic Practice and Action Research 11:9-21.

Checkland P, Scholes J (1990) Soft Systems Methodology in Action. Wiley, Chichester.

Choi S, Holmberg I, Lowstedt J, Brommels M (2011) Executive management in radical change - The case of the Karolinska University Hospital merger. Scandinavian Journal of Management 27:11-23.

Cole M, Harris S, Bernerth J (2006) Exploring the implications of vision, appropriateness, and execution of organizational change. Leadership \& Organization Development Journal 27:352-367. 
Cite as: Pollack, J., Pollack, R. (2014) Using Kotter's Eight Stage Process to manage an organisational change program: presentation and practice. Systemic Practice and Action Research, DOI 10.1007/s11213-014-9317-0

Crampton S, Hodge J, Mishra J (1996). Transition - Ready or Not: The Ageing of America's Work Force. Public Personnel Management 25:243-256.

Crawford L, Morris P, Thomas J, Winter M (2006) Practitioner development: From trained technicians to reflective practitioners. International Journal of Project Management 24:722-733.

Day M, Atkinson D (2004) Large-scale Transitional procurement change in the aerospace industry. Journal of Purchasing \& Supply Management 10:257-268.

DeLong D (2004) Lost Knowledge: Confronting the Threat of an Aging Workforce. Oxford University Press, Cary.

Denning S (2001) The Springboard. Butterworth-Heinmann, Oxford.

Department of Education, Employment and Workplace Relations (2010) Employment Outlook for Financial and Insurance Services. Australian Government, Canberra.

Flood R (1999) Rethinking the Fifth Discipline: Learning within the unknowable. Routledge, London.

Goede M (2011) Globalization of small islands: the role models of Curacao. International Journal of Commerce and Management 21:192-212.

Gupta P (2011) Leading Innovation Change - The Kotter Way. International Journal of Innovation Science 3:141-149.

Hay G, Beattie R, Livingstone R, Munro P (2001) Change, HRM and the voluntary sector. Employee Relations 23:240-255.

Helm J, Remington K (2005) Effective Project Sponsorship: An evaluation of the Role of the Executive Sponsor in Complex Infrastructure Projects by Senior Project Managers. Project Management Journal 36:51-61.

Hillson D (2003) Extending the risk process to manage opportunities. International Journal of Project Management 20:235-240.

International Atomic Energy Agency (IAEA) (2004) The nuclear power industry's ageing workforce: Transfer of knowledge to the next generation (IAEA-TECDOC-1399). International Atomic Energy Agency, Viena.

Joffe M, Glynn S (2002) Facilitating change and empowering employees. Journal of Change Management 2:369-379.

Kotter J (1996) Leading Change. Harvard Business School Press, Boston.

Kotter J (2005) Our iceberg is melting. St. Martlings Press, New York.

Kotter J (2008) A sense of urgency. Harvard Business School Press, Boston.

Krail K (2005) Retaining the Retiring Nurse. Nurse leader 33-36.

Lau F (1999) Toward a framework for action research in information systems studies. Information Technology \& People 12:148-175.

Leonard D, Swap W (2004) Deep smarts. Harvard Business Review:88-97.

Lintukangas K, Peltola S, Virolainen V (2009) Some issues of supply management integration. Journal of Purchasing \& Supply Management 15:240-248.

Lubit R (2001) Tacit Knowledge and Knowledge Management: The Keys to Sustainable Competitive Advantage. Organizational Dynamics 29:164-178.

Malone D (2002) Knowledge Management: A model for organizational learning. International Journal of Accounting Information Systems 3:111-123.

Mento A, Jones R, Dirndorfer W (2002). A change management process: Grounded in both theory and practice. Journal of Change Management 3:45-59.

Midgley G (2003) Science as Systemic Intervention: Some Implications of Systems Thinking and Complexity for the Philosophy of Science. Systemic Practice and Action Research 16:77-97.

Molineux J, Haslett T (2002) Working Within Organizational Cycles - A More Suitable Way to Manage Action Research Projects in Large Organizations? Systemic Practice and Action Research 15:465-484.

Nitta K, Wrobel S, Howard J, Jimmerson-Eddings E (2009) Leading Change of a School District Organization. Public Performance \& Management Review 32:463-488.

Olsen K, Myers M (1999) Trying to improve communication and collaboration with information technology: An action research project which failed. Information Technology \& People 12:317-332.

Paper D, Rodger J, Pendharkar P (2001) A BPR case study at Honeywell. Business Process Management Journal 7:85-99.

Pfeifer T, Schnitt R, Voigt T (2005) Managing change: quality-oriented design of strategic change processes. The TQM Magazine 17:297-308. 
Cite as: Pollack, J., Pollack, R. (2014) Using Kotter's Eight Stage Process to manage an organisational change program: presentation and practice. Systemic Practice and Action Research, DOI 10.1007/s11213-014-9317-0

Phelan M (2005) Cultural Revitalization Movements in Organization Change Management. Journal of Change Management 5:47-56.

Pillay J, Hackney R, Braganza A (2012) Informing strategic IS change: Towards a 'metalearning' framework. Journal of Strategic Information Systems 21:58-71.

Productivity Commission (2005) Economic Implications of an Ageing Australia. Commonwealth of Australia, Canberra.

Raineri A (2011) Change management practices: Impact on perceived change results. Journal of Business Research 64:266-272.

Reissner S, Pagan V, Smith C (2011) 'Our iceberg is melting': Story, metaphor and the management of organisational change. Culture and Organization 17:417-433.

Remington K, Pollack J (2007) Tools for Complex Projects. Gower, Aldershot.

Roberto M, Levesque L (2005) The Art of Making Change Initiatives Stick. MIT Sloan Management Review 46:53-60.

Saka A (2003) Internal change agents' view of the management of change problem. Journal of Organizational Change Management 16:480-496.

Sankaran S and Tay B (2003) Action Research Models in Business Research. ANZSYS Conference. 1-19. Melbourne, Australia.

Sarah R, Haslett T, Molineux J, Olsen J, Stephens J, Tepe S, Walker B (2002) Business Action Research in Practice - A Strategic Conversation About Conducting Action Research in Business Organizations. Systemic Practice and Action Research 15:535546.

Sherman R (2008) Lost Knowledge: Confronting the Challenges of an Aging Nursing Workforce. Nurse Leader 45-56.

Sikorko P (2008) Transforming library and higher education support services: can change models help? Library Management 29:307-318.

Smith I (2011) Orgnaisational quality and organisational change: Interconnecting paths to effectiveness. Library Management 32:111-128.

Springer P, Clark C, Strohfus P, Belcheir M (2012) Using Transformational Change to Improve Organizational Culture and Climate in a School of Nursing. Journal of Nursing Education 51:81-88.

Stewart J, Kringas P (2003) Change Management - Strategy and Values in Six Agencies from the Australian Public Service. Public Administration Review 63:675-688.

Swepson P (2003) Some Common Ground that can provide a Basis for Collaboration between Action Researchers and Scientists: A Philosophical Case that Works in Practice. Systemic Practice and Action Research 16:99-111.

Tsoukas H, Papoulias D (2005) Managing Third-order Change: The Case of the Public Power Corporation in Greece. Long Range Planning 38:79-95.

Van der Meer F (1999) Evaluation and the Social Construction of Impacts. Evaluation 5:387406.

West D, Stansfield M (2001) Structuring Action and Reflection in Information Systems Action Research Studies Using Checkland's FMA Model. Systemic Practice and Action Research 14:251-281.

Yauch C, Steudel H (2002) Cellular manufacturing for small businesses: key cultural factors that impact the conversion process. Journal of Operations Management 20:593-617. 